\title{
Simulation Study of Aircraft AC Generator with Electrical Fault Insertion
}

\author{
Chethan Kumar T.R $^{\# 1}$, P.V.R Sai Kiran ${ }^{\# 2}$, N. Balasubramanian ${ }^{\# 3}$, Vanam Upendranath ${ }^{\# 4}$ \\ Structural Technologies Division, \\ CSIR-National Aerospace Laboratories \\ Bangalore 560017, India \\ 123.chethan@gmail.com, ${ }^{2}$ saikiran@nal.res.in, ${ }^{3}$ monabalu@gmail.com, ${ }^{4}$ vanam@nal.res.in
}

\begin{abstract}
The aim of this paper is to model a typical Aircraft Generator along with its control system and study the behaviour / performance during fault, particularly in the rectifier block which is used in the field circuit and fault in the winding. The study shows that there is no considerable change in the Generator supply characteristic up to a certain extent of fault, but the significant change in the field excitation was observed. The output of the developed model was successfully corroborated with the MIL-STD 704F power supply characteristics.
\end{abstract}

Keywords - Aircraft AC Generators, Control System, Matlab/Simulink

\section{INTRODUCTION}

Typical Aircraft Generator has three-stages [1] and is driven from the accessories gear box of the engine. Fig 1 schematically shows the system structure of the three-stage Generator. From the literature, it is seen that studies have been undertaken to examine the behaviour of Aircraft AC Generator with winding fault. They are limited to lower severity of winding faults. In this paper, an attempt has been made to simulate Aircraft AC generating system to a higher degree of winding fault. It also includes the behaviour of Generator with single diode fault.

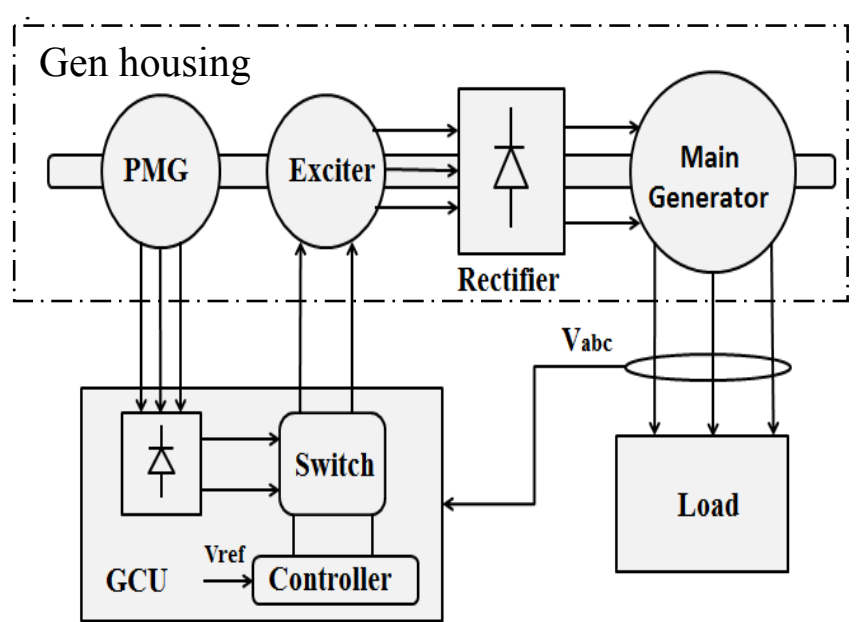

Fig.1Structure of three-stage Generator

\section{MODEL OF AIRCRAFT GENERATOR}

Typical Generator models have been described in [2]. Fig 3 shows a typical three phase, wye connected Generator. The stator windings are displaced $120^{\circ}$ between each phase. Each phase has resistance $r_{s}$ and equivalent Ns turns. The rotor has one field winding and two damping windings aligned with both $\mathrm{d}$ and $\mathrm{q}$ axis. The field winding can be represented by the resistance $\mathrm{r}_{\mathrm{fd}}$ and equivalent $\mathrm{N}_{\mathrm{fd}}$ turns. The two perpendicular damping windings, $\mathrm{kd}$ and $\mathrm{kq}$, are equal to resistance $\mathrm{r}_{\mathrm{kd}}$ and $\mathrm{r}_{\mathrm{kq}}$ with equivalent $\mathrm{N}_{\mathrm{kd}}$ and $\mathrm{Nkq}$ turns respectively. The direct axis ( $d$ axis) is the magnetic axis of $f_{d}$ and $k_{d}$ windings and the quadrature axis (q axis) is aligned with the magnetic axis of the $\mathrm{k}_{\mathrm{q}}$ winding. The equivalent circuit of three phase Generator is as shown in fig 4.

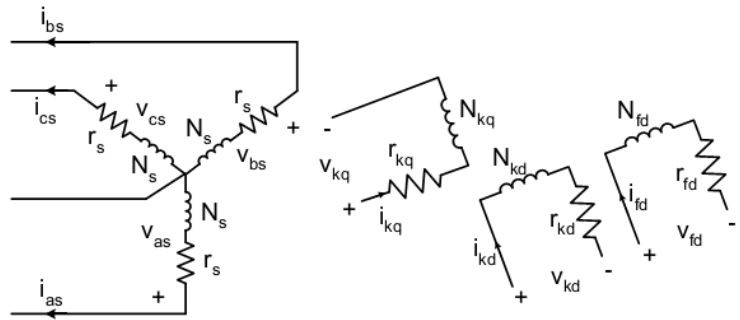

Fig.3 Typical three phase wye connected Generator.

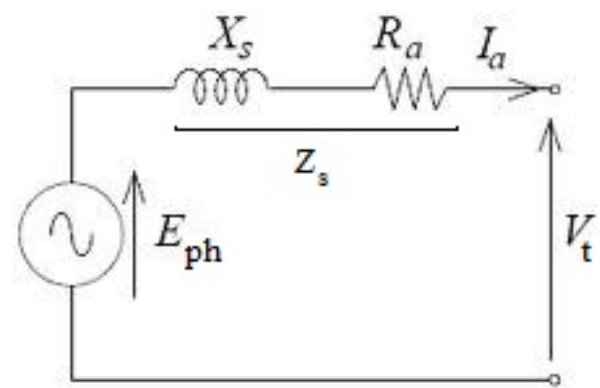

Fig.4 Equivalent circuit of a three phase Generator

The equation of a Generator is given by

$$
\mathrm{E}_{\mathrm{ph}}=\mathrm{V}_{\mathrm{tph}}+\mathrm{I}_{\mathrm{aph}} \mathrm{Z}_{\mathrm{s}}
$$

Where, $\mathrm{E}_{\mathrm{ph}}$ is the induced e.m.f per phase $\mathrm{V}_{\mathrm{tph}}$ is the terminal voltage per phase $I_{\text {aph }}$ is the armature current per phase 


\section{$Z_{\mathrm{s}}$ is synchronous impedance per phase}

Equation (1) can be written as

$$
\mathrm{V}_{\mathrm{tph}}=\mathrm{E}_{\mathrm{ph}}-\mathrm{I}_{\mathrm{a}} \mathrm{Z}_{\mathrm{s}}
$$

But, the induced phase emf is given by

$$
\mathrm{E}_{\mathrm{ph}}=\mathrm{K} \varnothing \omega_{\mathrm{m}}
$$

Where, $\mathrm{K}$ is a constant

$\omega_{\mathrm{m}}$ is the speed

$\varnothing$ is the magnetic flux

In the Equation (3), $\mathrm{K}$ is constant, and since the simulation is carried out for a Generator driven at constant speed, $\omega_{\mathrm{m}}$ remains constant. But the magnetic flux is directly proportional to the field current $\left(\mathrm{I}_{\mathrm{f}}\right)$. Therefore, to keep the terminal voltage at a constant rms value $\mathrm{I}_{\mathrm{f}}$ is varied. Thus the terminal voltage of an Aircraft Generator is maintained at a constant value within the response time constraint of the control system.

With the expedient information briefed in this section, the simulation model is developed as shown in the fig 5. It comprises permanent magnet Generator (PMG), exciter Generator, rectifier, main Generator and Generator control unit (GCU).

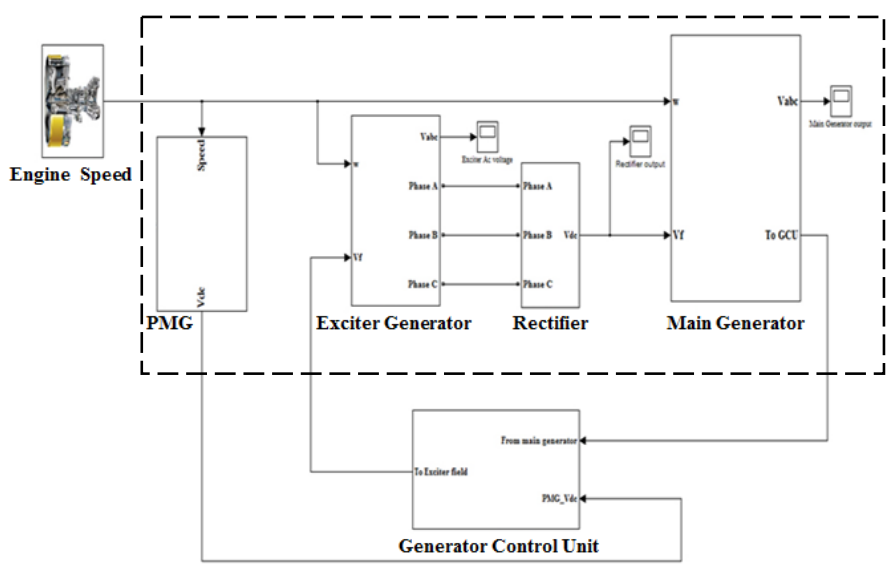

Fig.5 Simulation of Aircraft Generators

\section{CONTROL STRUCTURE}

\section{A. CONTROL REQUIREMENTS TO MEET MIL-STD 704F SUPPLY REQUIREMENTS}

The basic function and requirement for the controller is to maintain the given voltage at a constant level under various load conditions and to match the power supply requirement according to MIL-STD 704F. The voltage control is accomplished through adjusting the input current fed into the field of exciter Generator that controls the excitation of the main Generator. The average input current of the exciter's field is controlled by pulse width modulation technique through a time controlled electronic switch. Table 1 summarizes MIL-STD 704F power supply characteristics [4].

\begin{tabular}{|c|c|}
\hline Steady state characteristics & Limits \\
\hline Steady state voltage & 108.0 to 118.0 Volts, $\mathrm{RMS}$ \\
\hline Voltage unbalance & 3.0 Volts, RMS maximum \\
\hline Voltage modulation & 2.5 Volts, RMS maximum \\
\hline Transient characteristics & Limits \\
\hline Peak Voltage & \pm 271.8 Volts \\
\hline
\end{tabular}

TABLE I MIL-STD 704F power supply characteristics

\section{B. GENERATOR CONTROL UNIT}

The Generator controllers use the magnitude based analog control [3]. The beneficial information awaited from the Generator is the magnitude of its voltage. So the simplest way is by voltage regulation control. Fig 6 shows the block diagram of the controller. The GCU is modelled using a PI controller. This type of controller has relatively simple configuration and is therefore easier to implement. This can lead to cheaper solutions especially with regard to analog implementation. However, the tuning of control is timeconsuming and tedious. Through suitable design and tuning, the analog control can have an adequate dynamic performance, especially in the case of Aircraft Generators with constant frequency applications

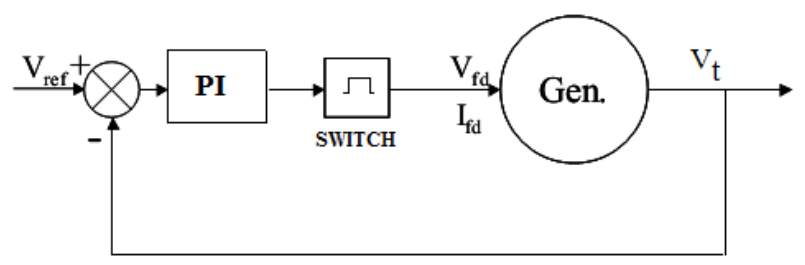

Fig .6 Block diagram of the controller

In the fig 6 , input to the controller is compared to a reference value and the error signal is given as the input to the PI controller. The PI controller's output is fed to the switching block. The switch is connected between the PMG and exciter Generator's field. A sawtooth wave is compared with the output of PI controller which generates the switching pulses controlling the on - off time of the switch. The average DC voltage to the exciter Generator's field is varied in this manner to vary the field current as required.

\section{LIMITATIONS ON CONTROLLER PERFORMANCE}

In the above section, the design of control loop is introduced. This control loop is dedicated to maintain steady state voltage 
and expedite the transit process. However, through the study of the output including faulty conditions, we found the limitation of system imposed on the control performance. In section $\mathrm{V}$ we present a classification of faults that may be encountered during the operation of Aircraft AC Generators injecting the faults into the developed model and study the control system performance under various faults.

\section{FAULT MODELLING}

Faults in the Aircraft Generators can arise in mechanical/structural system or in electrical system. Typical electrical system related faults can be in rotating rectifier diode failure (open or short), winding faults [5]. In mechanical aspects it could be bearing faults [6] or faults in structural integrity. In this paper, only the parametric faults related to electrical characteristics are considered while structural faults (bearing fault) are omitted. Diode fault is modelled as a single diode short in a three phase rectifier bridge used in the field excitation and is shown in the fig 7 . Winding faults can be field winding fault and armature winding fault. Winding fault may be due to the short in the windings. This is modelled as a reduction in the percentage of the winding (e.g.10\% of winding short).

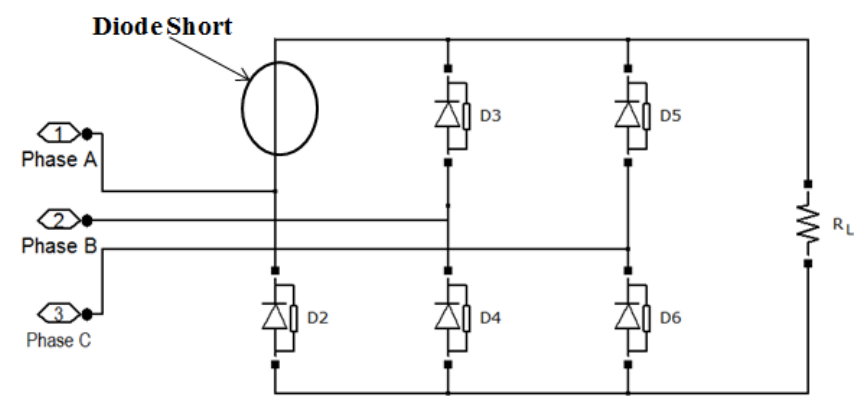

Fig.7 Single diode short

Our objective was to develop the model for a normal operation under varying load conditions and verify the performance with introduction of fault. This is presented in section VI.

\section{SIMULATION RESULTS}

The complete Aircraft AC Generator model of $400 \mathrm{~Hz}, 115$ $\mathrm{V}_{\mathrm{rms}}$ is simulated under healthy and faulty behaviour using $\operatorname{Matlab}^{\circledR} /$ Simulink $^{\circledR}[7]$.

\section{A. Healthy Operation}

The healthy operation is simulated for both constant and varying loads in order to demonstrate the working of the controller and to compare the healthy behaviour with faulty model. The model is simulated and the following observations are made. The output of the rectifier is a DC voltage (fig 8) stabilised after a transient period with very small ripple that are levelled by the capacitor connected in parallel at the output.

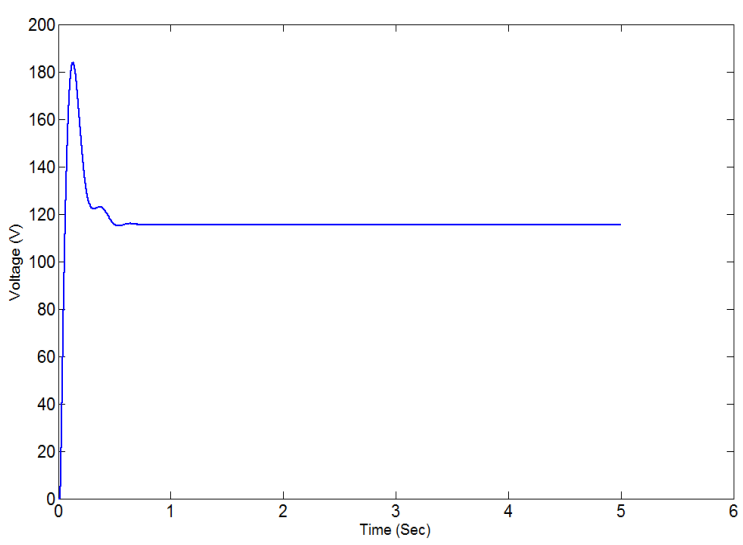

Fig.8 Rectifier output voltage

After the transient period, the three phase output of the main Generator for a constant load of $10 \mathrm{KW}$ is stabilized at 115 $\mathrm{V}_{\mathrm{rms}}$ as shown in the fig 9. When the load is increased in steps of $5 \mathrm{KW}$, it is seen that the controller takes $0.5 \mathrm{sec}$ to stabilize the output of main Generator. The three phase output of main Generator under variable load is shown in the fig 10.

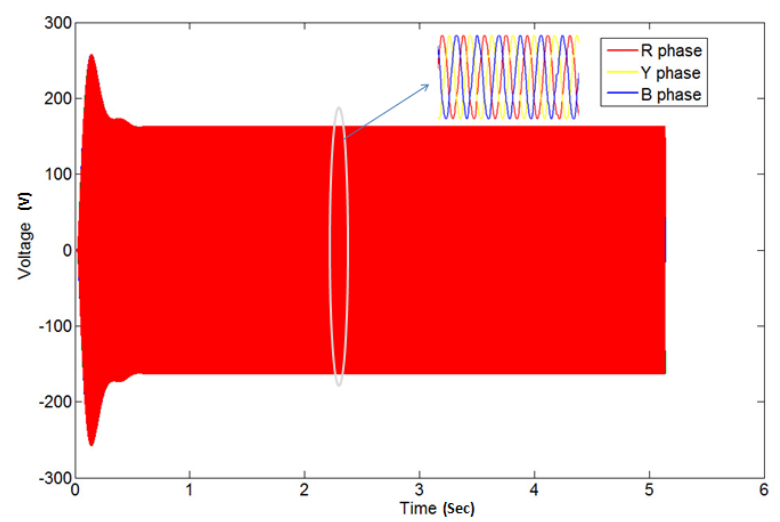

Fig.9 Main Generator output voltage for $10 \mathrm{Kw}$ resistive load

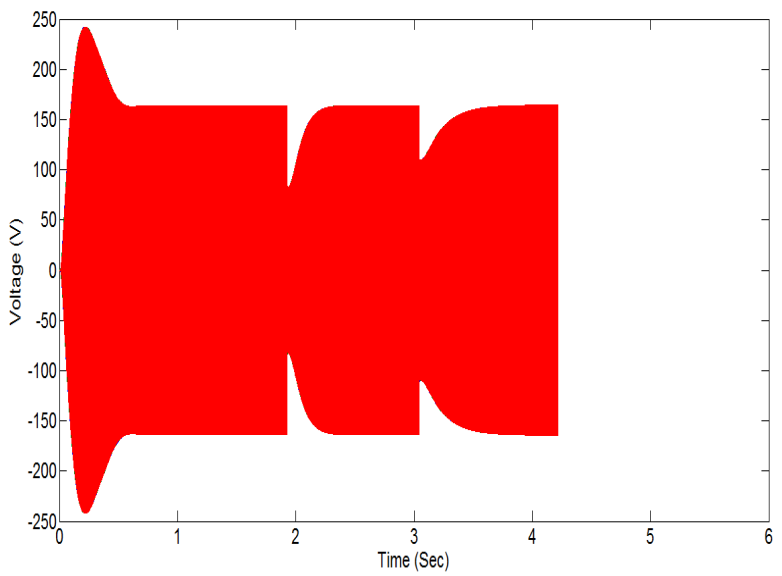

Fig.10 Main Generator output voltage for varying load 


\section{B. Faulty Operation}

The faults discussed in the section $\mathrm{V}$ have been injected in the model at time $\mathrm{t}=2.5 \mathrm{sec}$.

Diode fault: Single diode fault is simulated as shown in the fig 7. The rectifier output voltage decreases when the fault is injected. Due to the controller action, the decreased DC output voltage is stabilized to steady state voltage. The output is shown in the fig 11. Due to the injection of this fault, the three phase output of the main Generator is disturbed by a small amount for a shorter transient period which is well within the limit of MIL-STD 704F. The output of main Generator is shown in fig 12. Similarly single diode open fault has the insignificant effect in the supply characteristics.

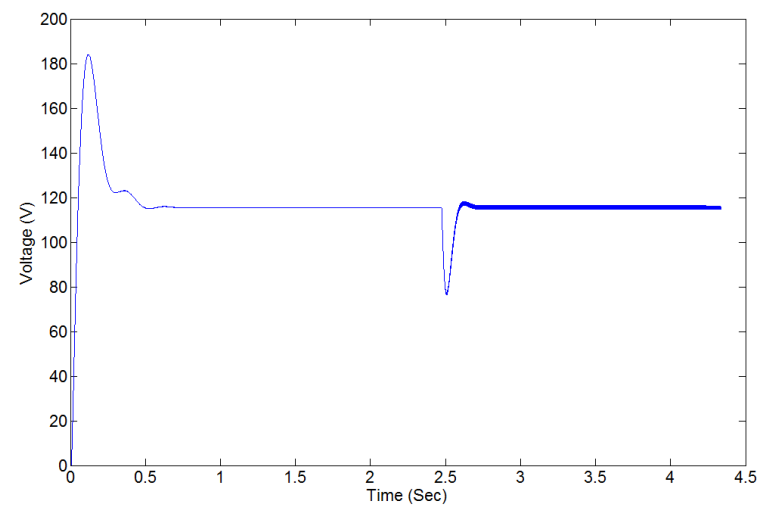

Fig.11 Rectifier output voltage- single diode short

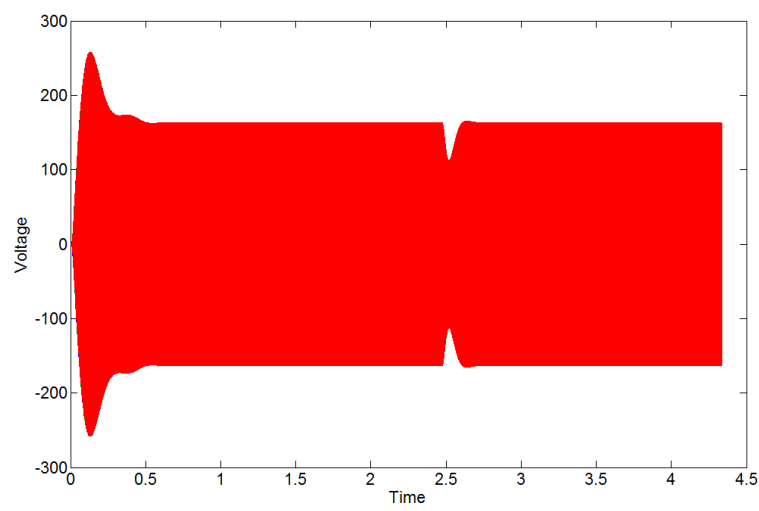

Fig.12 Main Generator voltage- single diode short

Winding fault: This type of fault is injected by a partial decrease in the effective number of turns of the field winding of the main Generator. In practice this may be due to the shorted turns. The fault is injected at time in between $\mathrm{t}=2.25$ and $\mathrm{t}=2.75 \mathrm{sec}$ in the form of decrease in the percentage of winding. The field winding is shorted for 10percent, 20percent, 30percent, 40percent, and 50percent. It is observed that till 40percent of shorted turns the controller stabilizes the output of rectifier within a shorter time period, but after 40percent the output of the rectifier is not stabilized. The figures from 13-22, show the output voltage of the main Generator under winding fault condition.

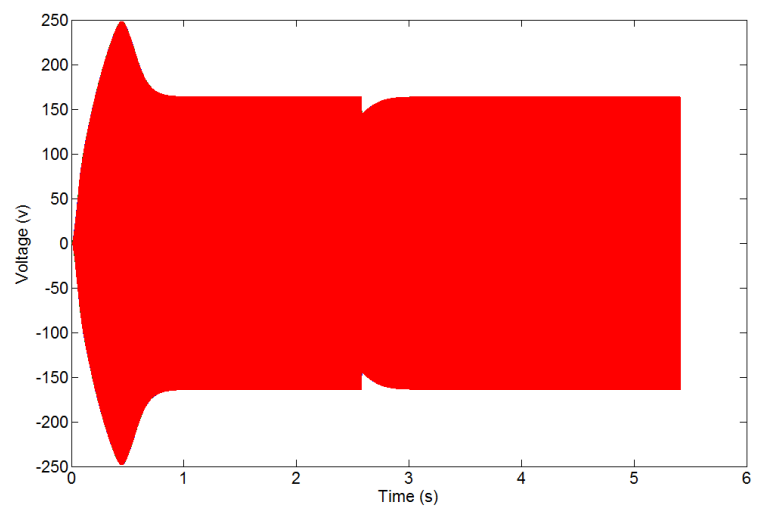

Fig.13 Main Generator output -10\% Field winding turn fault

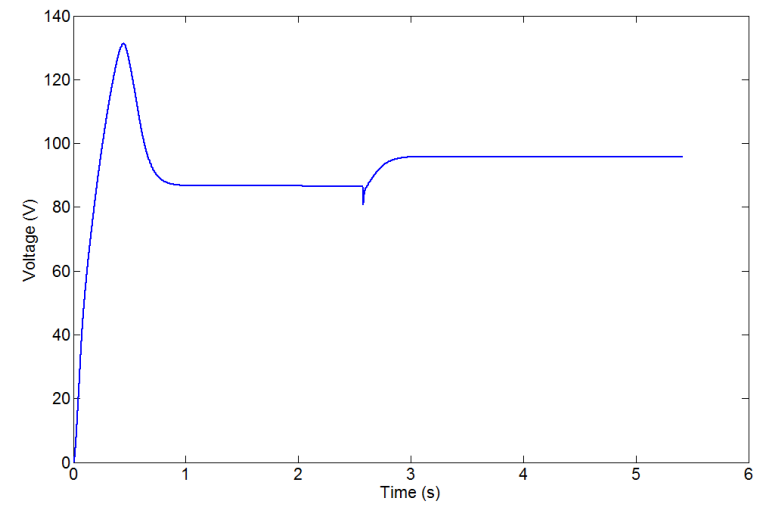

Fig.14 Rectifier output voltage-10\% Field winding turn fault

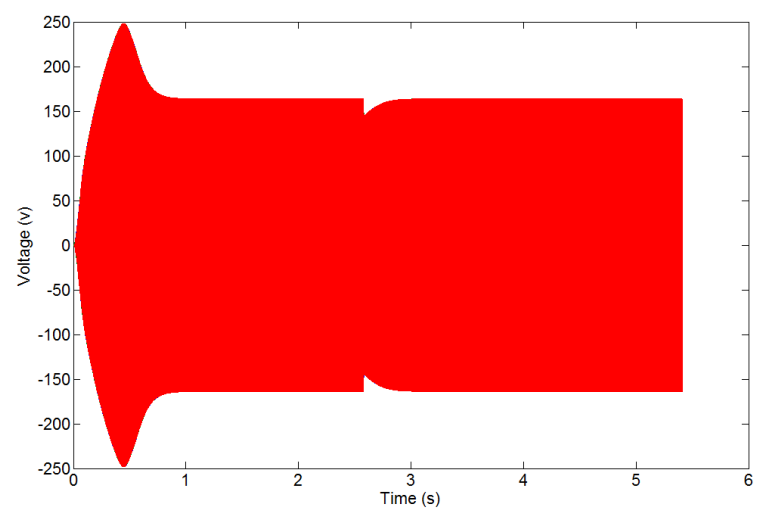

Fig. 15 Main Generator output -20\% Field winding turn fault 


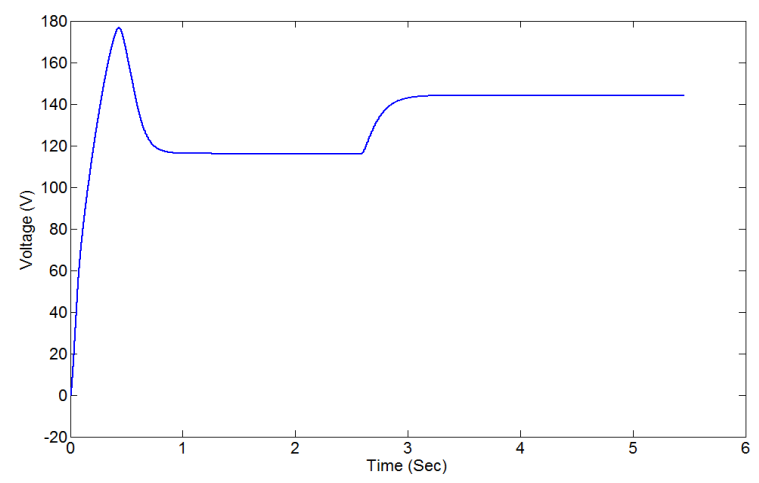

Fig.16 Rectifier output voltage- $20 \%$ Field winding turn fault

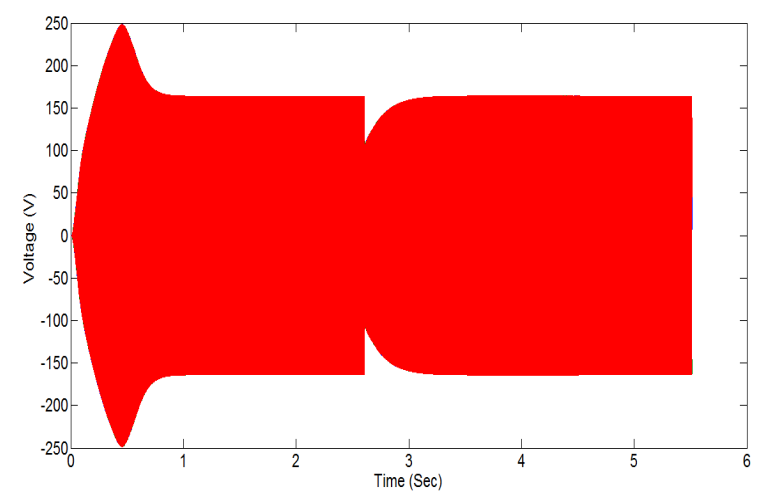

Fig. 17 Main Generator output -30\% Field winding turn fault

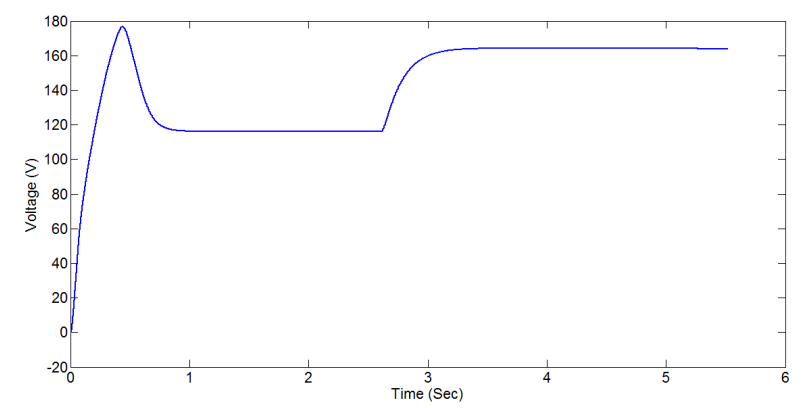

Fig.18 Rectifier output voltage- 30\% Field winding turn fault

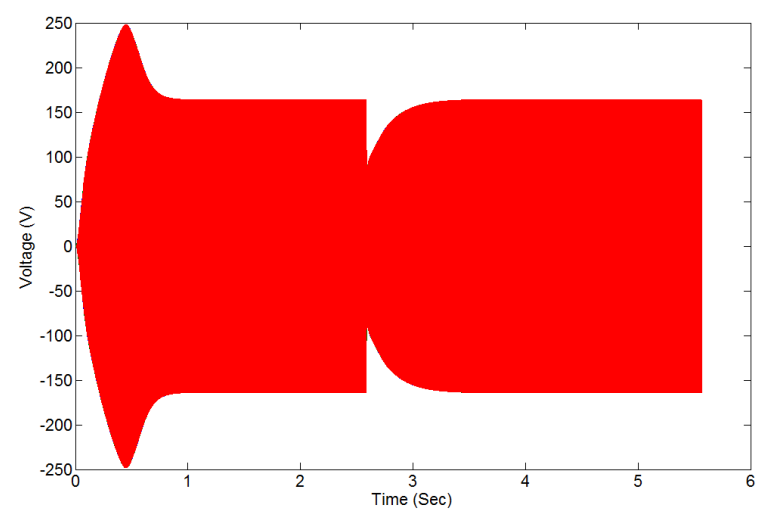

Fig.19 Main Generator output -40\% Field winding turn fault

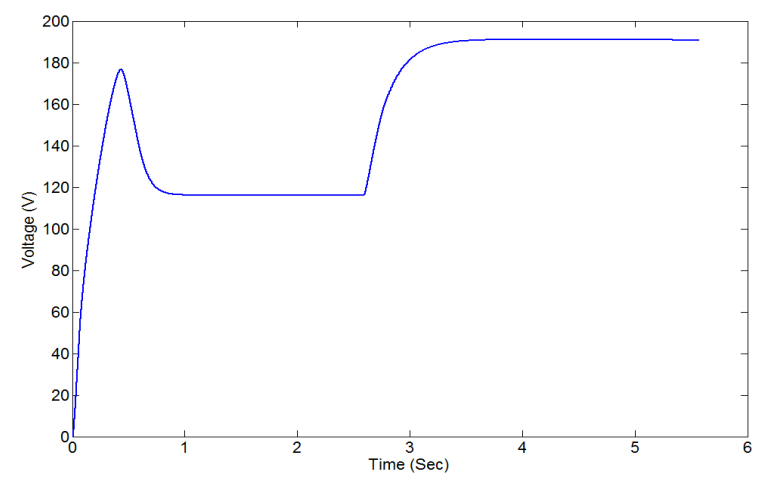

Fig.20 Rectifier output voltage- $40 \%$ Field winding turn fault

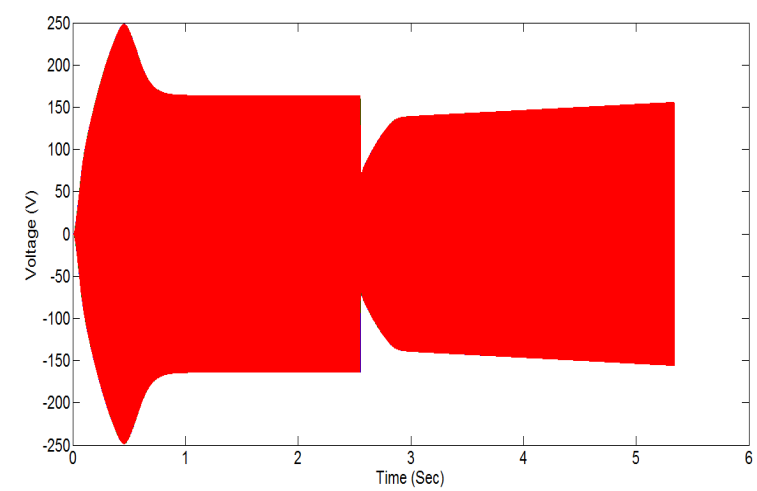

Fig.21 Main Generator output $-50 \%$ Field winding turn fault

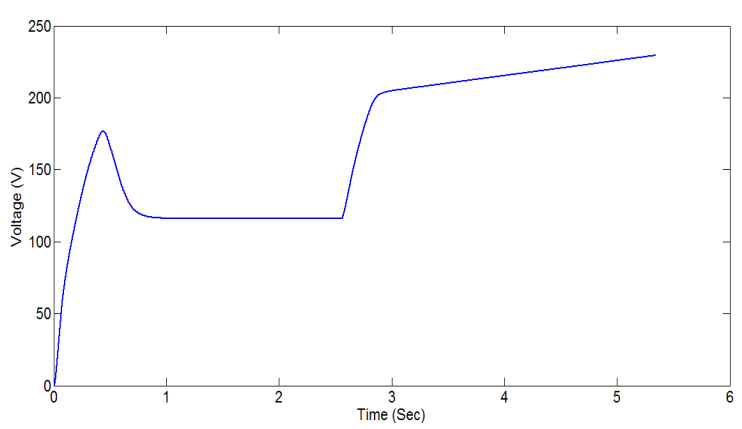

Fig.22 Rectifier output $-50 \%$ Field winding turn fault

\section{CONCLUSIONS}

From the above study following are observed.

1. Single Diode fault does not have effect in the Generator supply characteristics

2. Winding fault up to $40 \%$ loss of the winding turns has least effect on the Generator supply characteristics

3. Adequately over rated diodes, PMG power supply capability can ensure a robust design of the generating system

However under fault conditions significant increase in the field voltage is observed. This is caused by the control system to maintain the supply characteristics within the limit. 
For monitoring the health of the Generator significant change in the field excitation parameters is a pointer for the derangement in the Generator.

\section{ACKNOWLEDGMENT}

The authors are grateful to the Head, STTD, CSIR-NAL Bangalore, NPMASS and the Director, CSIR-NAL, for their generous support and encouragement.

\section{REFERENCES}

[1] Hansen, Beach, Plencner, Dengler, Jefferies, Frye, (1985) "Advanced secondary power system for transport Aircraft," in IEE Colloquium on All Electric Aircraft,(June 1995)

[2] P.C. Krause, O. Wasynczuk, S. Sudhoff, "Analysis of electric Machinery and Drive Systems", 2nd ed., IEEE-Press \& Wiley Interscience, 2002

[3] P. Kundar, "Excitation Systems", in Power System Stability, McGrawHill, Inc., 1993, pp. 315-377

[4] MIL-STD-704F, Department of Defence Interface Standard.

[5] J. Sottile, F. C. Trutt, A. W. Leedy "Condition Monitoring of Brushless Three-Phase Synchronous Generators with Stator Winding or Rotor Circuit Deterioration"

[6] Jae-Won Choi, "Analysis of Electrical Signatures in Synchronous Generators Characterized by Bearing Faults"

[7] The MathWorks, Inc. Simulink V7.7 (R2011a).

[8] Kirby Keller et al., Aircraft Electrical Power Systems Prognostics and Health Management, IEEE aerospace conference 2006

\section{BIOGRAPHIES}

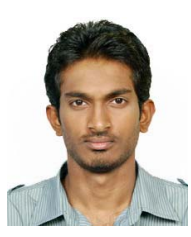

Chethan Kumar T.R is currently working as a Graduate Trainee in CSIR-National Aerospace Laboratories, India. Awarded Bachelors in Electrical \& Electronics Engineering from VTU in 2012.His interests are in the areas of electrical machines, control systems and power electronics.

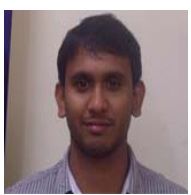

P V R Sai Kiran is currently working as scientist in CSIRNational Aerospace Laboratories(NAL), India. He received his M.Tech in Machine Drives \& Power electronics from IIT Kharagpur and has received Bachelor's degree in Electrical \& Electronics Engineering from JNTU. Recipient of outstanding performance award in Design, Development and project execution for the Project of "Development of Electronics for harnessing data from MEMS pressure sensors on LCA Aircraft". His main interests are in the areas of fault diagnosis, prognosis and Aircraft Electrical system health management.

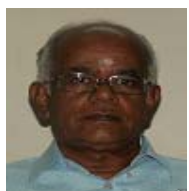

N Balasubramanian is currently working as specialist consultant in National Aerospace Laboratories, India. Prior to this assignment he had worked as Additional general manager in Aircraft Research and Development
Complex, Hindustan Aeronautics Ltd. He has 37 years of experience in Aircraft systems of which last 20 years he was involved in development of Utility Systems management Units for Light Combat Aircraft (LCA). His main interests are in the areas of Aircraft system engineering.

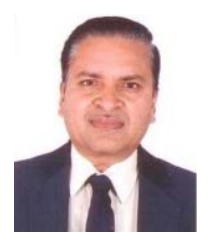

Vanam upendranath is a senior principal scientist in Structures Division at CSIR-National Aerospace Laboratories (NAL), India. He is the project coordinator of NPMASS (National Program on Micro and Smart Systems) IVHM projects and is also in-charge of the IVHM Mission initiated at CSIR-NAL. Upendranath did his Masters in Electronics from REC (NIT) Warangal in 1981 and $\mathrm{PhD}$ in 2005 on Italian in Govt fellowship at Univ of Trento, and IRST Trento, Italy. During his PhD tenure, he was also a visiting researcher at Johns Hopkins university, Baltimore USA. He is also a senior member of IEEE, fellow of IETE and an elected member of Aeronautical society of India. His main area of interest is IVHM applications for aerospace. 